\title{
Evaluation of wild herbivore faeces from South Africa as a potential source of hydrolytically active microorganisms
}

\author{
Luyanda L. Ndlela and Stefan Schmidt ${ }^{*}$
}

\begin{abstract}
This study assessed faecal matter from three indigenous South African herbivores—zebra, giraffe and impala—as a potential source for hydrolytically active aerobic and facultatively anaerobic bacteria. Herbivore droppings were collected freshly in a local nature reserve in Pietermaritzburg, South Africa. Soil samples adjacent to faecal collection sites and faeces from a domestic herbivore, the Nguni cow, were included as controls. Hydrolase and dehydrogenase activity in faecal matter and soil samples were measured by the fluorescein diacetate and the triphenyltetrazolium chloride assay. Viable counts and counts for amylase, cellulase, esterase and protease producers were established using plate count agar and solid media containing cellulose, skim milk, starch and Tween 80. Zebra droppings produced the highest hydrolase and dehydrogenase activity. Faecal matter of the three indigenous herbivores generally produced higher hydrolytic activity than Nguni cow faeces and soil controls, thereby confirming that these materials are potential targets for hydrolytic enzyme mining.
\end{abstract}

Keywords: Fluorescein diacetate, Triphenyltetrazolium chloride, Hydrolases, Zebra, Giraffe, Impala, Nguni, Faeces

\section{Background}

Hydrolytic enzymes or hydrolases are biocatalysts that break covalent bonds by using water as co-substrate. Many hydrolytic enzymes are essential for microorganisms by enabling the utilization of organic polymers such as cellulose or starch as carbon and energy source. At the same time hydrolytic enzymes of microbial origin are applied in numerous industrial processes such as the production of food and beverage, the degradation and recycling of organic waste or the transformation of cellulosic materials into glucose for biofuel production (Bhaskar et al. 2008; Kirk et al. 2002; Gupta et al. 2002; Morrison et al. 2009). This indicates that the screening of microbes as source for such hydrolytic enzymes has economic potential. As industrial processes require enzymes able to perform optimally under specific physical and chemical parameters such as high temperatures or salinity, a potentially better option than adjusting process

\footnotetext{
*Correspondence: schmidts@ukzn.ac.za

Discipline of Microbiology, School of Life Sciences, University of KwaZuluNatal, Private Bag X01, Pietermaritzburg 3209, South Africa
}

parameters is to search for suitable novel hydrolytic enzymes from microbial sources (Kirk et al. 2002; Cherry and Fidantsef 2003; Sanchez-Porro et al. 2003).

Faecal matter, particularly from wild herbivores such as zebra, giraffe and impala, has not been extensively studied as a source for the isolation of hydrolytic microorganisms while for domestic animals many such studies were reported (Blackburn and Hobson 1962; Varel et al. 1984; Gong 2007). A study investigating environmental sources for cellulolytic microorganisms found more than 20 different cellulolytic microbial species of which at least two were from bovine faeces (Doi 2008). Such findings highlight the potential of various faecal materials as potential sources of industrially applicable hydrolytic microbial enzymes. So far, only a few publications reported on the presence of cellulolytic hydrolytic microorganisms in zebra faeces (Sadhu et al. 2011; Laho et al. 2012). However, data are lacking on the presence of proteolytic, lipolytic or amylolytic microorganisms in zebra faeces and essentially no data are available for giraffe or impala faeces. Based on their diet comprising grasses, evergreen leaves and other shrubbery high in fibre (Pellew 1984;

\section{至 Springer}


Keesing 1998; de Garine-Wichatitsky et al. 2004), it is highly likely that these herbivores possess active cellulolytic microbes in their faeces.

Cellulolytic microorganisms have been put under the spotlight due to the increasing need to generate renewable energy from cellulose containing organic waste (Juturu and Wu 2014). These microorganisms are involved in biofuel generation by hydrolysing cellulosic plant waste material, which is an essential part of the first hydrolysis step of the so-called anaerobic food chain. Apart from cellulases, three other major groups of hydrolases are used in industrial processes; esterases, amylases and proteases (Kirk et al. 2002; Ray 2011).

This study therefore screened fresh faecal matter of three indigenous South African herbivores, zebra (Equus burchelli), giraffe (Giraffa camelopardalis) and impala (Aepyceros melampus), for the presence of protease-, amylase-, esterase- and cellulase-producing aerobic and facultatively anaerobic microorganisms to verify the potential of this material as a source for such hydrolase producing microorganisms and their enzymes.

\section{Results}

Moisture, $\mathrm{pH}$ and sCOD of faeces and soil samples

The $\mathrm{pH}$ of fresh faecal samples including Nguni cow faeces was in a range from 7.34 to 8.32 , with impala and zebra faeces having a similar, slightly alkaline $\mathrm{pH}$ (Table 1). In contrast, all control soil samples analysed were slightly acidic ( $\mathrm{pH}$ range 5.81-6.34). The sCOD of zebra, giraffe and impala faeces was clearly higher (57 and $80 \mathrm{mg} / \mathrm{g}$ ) than the sCOD of the matching soil samples $(\leq 9 \mathrm{mg} / \mathrm{g})$. This is indicative of the difference in soluble organic matter content between the collected surface soil and faeces. The cow faecal material had a much higher sCOD $(339 \mathrm{mg} / \mathrm{g})$ than the wild ungulate faeces and the highest moisture content (54\%), whilst the $\mathrm{pH}$ was near neutral and similar to that of giraffe faeces. Zebra faeces

Table 1 Average pH, moisture content and sCOD of freshly collected zebra, giraffe, impala and cow faeces and matching soil samples

\begin{tabular}{lccc}
\hline Source & $\mathbf{p H}$ & $\begin{array}{l}\text { Moisture } \\
\text { content (\%) }\end{array}$ & $\begin{array}{l}\mathbf{s C O D} \\
\mathbf{( m g / g )}\end{array}$ \\
\hline Zebra faeces & 8.18 & 49 & 80 \\
Zebra soil control & 5.81 & 4 & 7 \\
Impala faeces & 8.32 & 30 & 57 \\
Impala soil control & 6.34 & 7 & 9 \\
Giraffe faeces & 7.34 & 27 & 73 \\
Giraffe soil control & 5.95 & 4 & 8 \\
Cow faeces & 7.39 & 54 & 339 \\
\hline
\end{tabular}

All data shown are the means of measurements performed on samples collected on four different occasions had the highest moisture content of the wild ungulates (49\%), while giraffe and impala faeces were almost identical with 27 and $30 \%$ moisture content respectively. Generally, soil samples had the lowest moisture content, a more acidic $\mathrm{pH}$ and a much lower sCOD in comparison to the faecal samples, highlighting the apparent differences between the composition of the herbivore faeces and the soil samples.

\section{Enzymic activity of faeces and soil samples}

In the FDA assay, samples subjected to shaking during incubation showed higher hydrolytic activities than samples incubated under static conditions (Fig. 1a), which is in line with previous reports in the literature (Schnurer and Rosswall 1982). Overall, faecal samples exhibited higher hydrolytic activity than soil samples, which is expected on microbiological grounds given that the intestinal microbial community is involved in breaking down organic polymers. Under shaking conditions, zebra faeces showed the highest hydrolytic activity at $1228 \mu \mathrm{g} \mathrm{g}^{-1} \mathrm{~h}^{-1}$, followed by giraffe at $1095 \mu \mathrm{g} \mathrm{g}^{-1} \mathrm{~h}^{-1}$ and impala at $905 \mu \mathrm{g} \mathrm{g}^{-1} \mathrm{~h}^{-1}$. The impala soil control had the highest activity $\left(121 \mu \mathrm{g} \mathrm{g}^{-1} \mathrm{~h}^{-1}\right)$ of all control soil samples. The large differences between the hydrolytic activities of faeces and the matching soil controls highlighted the different microbial activity and abundance in these two materials. Although the Nguni cow faeces yielded a lower hydrolytic activity than the faeces of the other three ungulates analysed, its activity was higher than that of soil control samples, again indicating the expected higher abundance of hydrolytically active microorganisms in faecal matter.

Samples were also analysed for dehydrogenase activity using the TTC assay. The results (Fig. 1b) indicated that faecal samples-very much like the results obtained for the FDA assay-had a much higher enzymic activity than soil control samples. Addition of glucose to samples prior to incubation resulted in greater TPF yields via dehydrogenase activity than for samples incubated without glucose added. The highest dehydrogenase activity without glucose added was observed in zebra faeces. A comparison between the different soil controls indicated that the giraffe soil control had a somewhat higher dehydrogenase activity than the other soils. The dehydrogenase activity in Nguni cow faeces was higher than that in soils but was lower than the activity found in the faeces of the wild ungulates, which is again similar to the results obtained for the FDA assay.

\section{Enumeration of hydrolytic bacteria}

In addition to enzymic activity, total and specific (hydrolase producing) aerobic viable counts were established 
(a)

$$
\begin{array}{r}
\text { Cow } \\
\text { Cow faeces (static) } \\
\text { Cow faeces (shaker) }
\end{array}
$$

Impala

Impala soil control (static)

Impala soil control (shaker)

Impala faeces (static)

Impala faeces (shaker)

Giraffe

Giraffe soil control (static)

Giraffe soil control (shaker)

Giraffe faeces (static)

Giraffe faeces (shaker)

Zebra

Zebra soil control (static)

Zebra soil control (shaker)

Zebra faeces (static)

Zebra faeces (shaker)

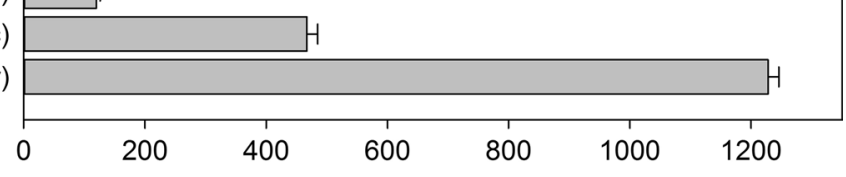

FDA hydrolysis [ $\mu \mathrm{g}$ fluorescein per hour per gram dry weight]

(b)
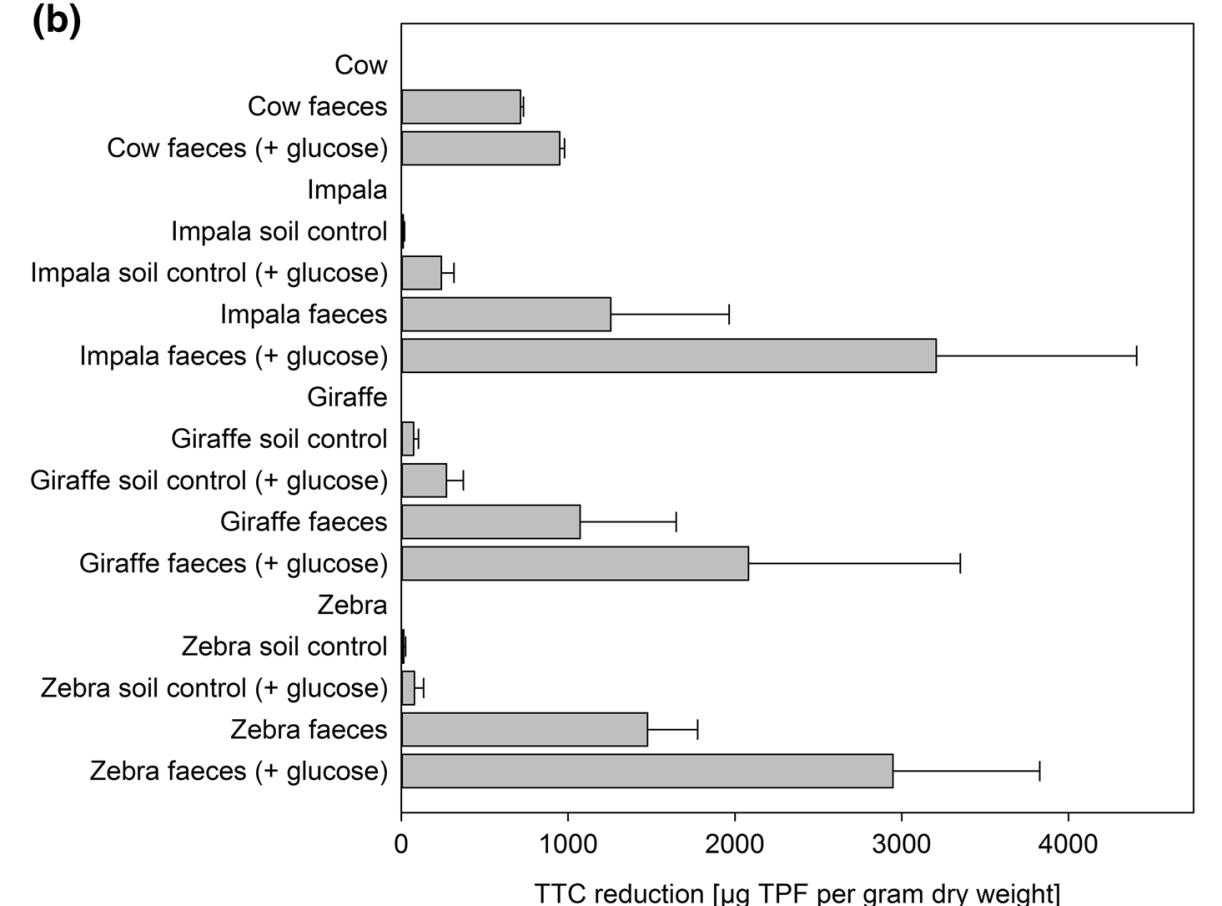

Fig. 1 a Hydrolase (FDA) activities of fresh faeces and matching soil samples. b Dehydrogenase (TTC) activities of fresh faeces and matching soil samples. Error bars indicate the standard error

(Table 2) as $\log _{10}$ cfu per gram dry weight of faeces or soil. The PC agar used is a general-purpose medium providing an estimate of the total microbial burden present whilst the different hydrolase targeting media used provide estimates for microorganisms producing cellulases, amylases, proteases and esterases. Faecal and soil samples contained all of the targeted hydrolase producers, albeit in varying proportions. The total viable plate counts (PC 
Table 2 Aerobic viable count $\left(\log _{10}\right.$ cfu per $g$ dry weight) \pm standard error of fresh faecal samples and matching soil controls using plate count and hydrolase specific agar

\begin{tabular}{llllll}
\hline Sample & PC agar & Starch agar & Skim milk agar & Tween 80 agar & CMC agar \\
\hline Giraffe & $8.53 \pm 6.16$ & $8.51 \pm 6.00$ & $8.50 \pm 5.76$ & $7.78 \pm 5.08$ & $8.40 \pm 5.95$ \\
Giraffe soil & $6.50 \pm 3.99$ & $6.49 \pm 4.08$ & $6.30 \pm 4.25$ & $6.20 \pm 3.95$ & $6.16 \pm 3.95$ \\
Impala & $8.29 \pm 6.18$ & $8.25 \pm 5.76$ & $8.24 \pm 6.25$ & $6.53 \pm 3.95$ & $8.01 \pm 5.95$ \\
Impala soil & $6.27 \pm 3.57$ & $6.10 \pm 3.57$ & $6.07 \pm 4.50$ & $<4$ & $6.16 \pm 4.18$ \\
Zebra & $8.30 \pm 5.64$ & $8.13 \pm 5.76$ & $7.52 \pm 6.32$ & $8.16 \pm 5.95$ & $7.63 \pm 4.95$ \\
Zebra soil & $6.68 \pm 4.18$ & $5.92 \pm 3.58$ & $5.09 \pm 3.00$ & $<4$ & $7.29 \pm 3.50$ \\
Cow & $8.13 \pm 5.49$ & $7.79 \pm 5.34$ & $6.76 \pm 4.27$ & $7.59 \pm 5.36$ & \\
\hline
\end{tabular}

$<4=$ lower than detection limit of $10^{4} \mathrm{cfu} / \mathrm{g}$ dry weight

CMC carboxymethyl cellulose agar, $P C$ plate count agar, cfu colony forming units

agar) of all faecal samples analysed were established in a similar range of log 8.13-8.53 (Table 2), with giraffe having the highest microbial count and Nguni the lowest. The total viable plate counts of surface soil samples were generally about two logs lower. Regarding the counts for different hydrolase producing bacteria, again, the faecal samples showed the highest levels and the soil samples the lowest (Table 2). However, in most cases the counts for different hydrolase producers from Nguni faeces were lower than the hydrolase producer counts obtained for wild ungulate faeces.

Relative abundances of specific hydrolase producing microbes were obtained by taking the colony forming units on PC agar as the total number (100\%) of viable aerobic and facultatively anaerobic microorganisms (Fig. 2). Only the giraffe soil control contained all the targeted enzyme producers while for the other two control soils the counts for esterase-producing microorganisms

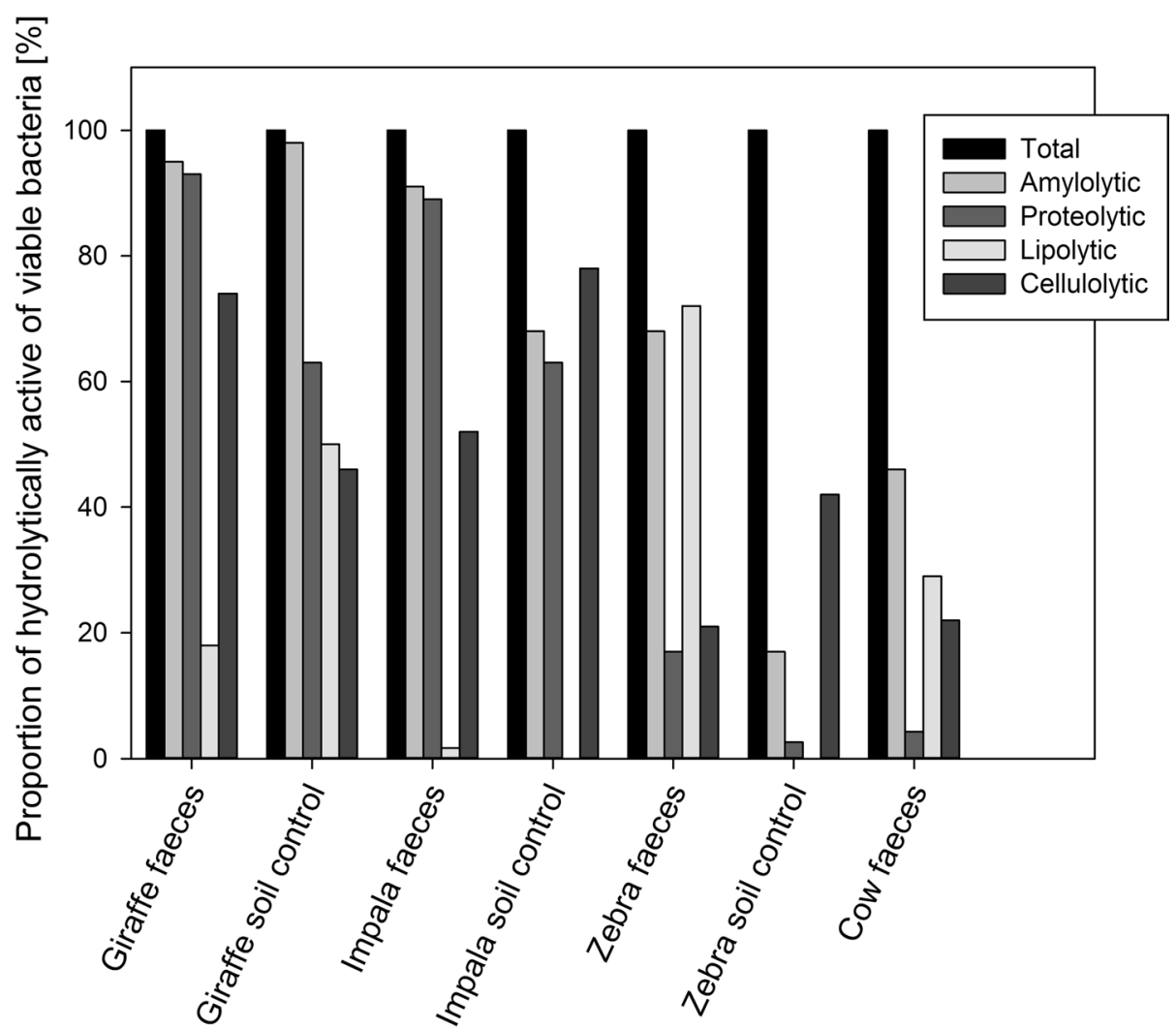

Fig. 2 Abundance of organic polymer-hydrolysing microorganisms in fresh faeces and matching control soil samples as percentage of the aerobic plate count (100\%) 
were below the detection limit. Faecal samples contained all the targeted hydrolase producers, with varying proportions of each hydrolase producer present in faeces of each individual animal. While giraffe and impala faeces showed similar overall proportions of hydrolase producers with the exception of lipolytic organisms which were lower in impala, both of them had higher proportions of amylase and protease-producers, with esterase-producers comprising the smallest group. Faeces of zebra and Nguni cow showed similar patterns with esterase and amylase producers as the largest and protease producers as the smallest group of the total viable count. Comparing the relative abundance of hydrolase producers and their counts to hydrolase activity determined indicated that enzymic activity was apparently linked to the overall microbial burden and not to one specific group of hydrolase producers.

\section{Discussion}

Faecal samples analysed in this study were compared with soil collected from the same area to verify whether the surrounding surface soil differs from faecal matter regarding the microbial burden and enzymic activities. In addition, Nguni cow dung enabled a comparison of the wild herbivore faeces to that of a domestic herbivore fed on a fibrous diet.

\section{Properties of faeces}

The neutral to slightly alkaline $\mathrm{pH}$ of the giraffe and Nguni cow faeces (Table 1) was within the expected $\mathrm{pH}$ range of ruminants, which is typically between 6 and 8 (Artan et al. 1996; Moran 2005; Marãnón et al. 2006). Zebra and impala faeces had a slightly more alkaline $\mathrm{pH}(>8)$, possibly indicating the presence of alkali-tolerant microorganisms therein. Soluble chemical oxygen demand (sCOD) values indicated the potential availability of substrate in the faeces enabling growth of heterotrophic microorganisms. The soil samples had a more acidic $\mathrm{pH}$ and much lower moisture and soluble COD content than the faecal samples at the time of sampling, matching properties reported for infertile dry soils that have a low water binding capacity (Hartemink 2006, 2007). The highest sCOD of $339 \mathrm{mg} / \mathrm{g}$ was determined for Nguni cow faeces, while the sCOD values of the other faeces ranged between 57 and $80 \mathrm{mg} / \mathrm{g}$. These values are within the expected sCOD range of 30-6000 $\mathrm{mg} / \mathrm{l}$ reported for cattle in other studies (Marãnón et al. 2006; Abubakar and Ismail 2012). The higher moisture content in faecal samples indicated that the nature of the herbivore diet was mostly water binding fibrous material due to the uptake of grasses and leaves (Ziemer et al. 2012). As a result, for all the animals analysed in this study, faecal matter had higher moisture percentage values than matching soils samples. Based on the moisture content, $\mathrm{pH}$ and $\mathrm{sCOD}$, faecal material clearly differed from the surrounding soil.

\section{Analysis of enzymic activity}

Microbial activity of samples was estimated through colorimetric assays that yield coloured reaction products once hydrolysis (FDA) or reduction (TTC) occurred. The fluorescein diacetate assay operates on the principle of hydrolytic release of two acetate groups via ester bond cleavage by free and membrane-bound hydrolytic enzymes, yielding the yellow-green coloured fluorescein that can be measured at $490 \mathrm{~nm}$ (Adam and Duncan 2001). FDA is a versatile substrate used for the detection of esterases within water bodies and individual cells (Battin 1997) and in soils (Green et al. 2006). However, other hydrolytic enzymes such as amylases can cleave its ester bonds as well (Lundgren 1981; Green et al. 2006). The FDA hydrolysis assay has also been utilised and recommended as an efficient method to estimate active cells within environmental samples (Swisher and Carroll 1980). The protocol employed in this study was optimised from Schnurer and Rosswall (1982) as suggested by Green et al. (2006) to establish the best possible assay conditions. Thus, acetone volumes used to terminate reactions were reduced to $4 \%(\mathrm{v} / \mathrm{v})$ and readings were taken within 30-60 min of termination to enable stable results (Green et al. 2006). As the FDA assay can be problematic due to abiotic cleavage caused by media components (Clarke et al. 2001; Wanandy et al. 2005), this was accounted for through use of an appropriate buffer and controls accounting for abiotic cleavage.

The FDA assay demonstrated that faecal samples from wild herbivores had higher hydrolase activity than soil controls and cow faeces, which is expected on microbiological grounds (Fig. 1a). In addition, samples incubated under shaker conditions showed higher activity than those incubated statically (Fig. 1a). Although this is contrary to the findings of Green et al. (2006) who reported that shaking decreased the amount of fluorescein released in soil samples, it confirms recommendations by Swisher and Carroll (1980) and Schnurer and Rosswall (1982) that shaking during incubation increases hydrolytic activity due to improved homogenisation. In addition, shaking improved the activity of hydrolytic microorganisms (Bozic et al. 2011) and substrate distribution (Juergensmeyer et al. 2007). The fact that a control with autoclaved faeces yielded no measurable activity in the FDA assay confirmed that its hydrolysis depended on the presence of hydrolytically active microorganisms or their enzymes in the faeces. Furthermore, the higher hydrolytic activity in faecal samples suggested that more hydrolase producing microorganisms were present in faeces than in soil as was confirmed by the plate counts (Table 2). Again, this is 
not unexpected as an increased degree of FDA hydrolysis relies on the presence of metabolically active microorganisms (Chrzanowski et al. 1984).

The TTC assay operates on the principle of reduction of colourless 2,3,5-triphenyltetrazolium chloride by active dehydrogenases to produce the corresponding coloured triphenylformazan (TPF). The water insoluble TPF can be extracted from samples using solvents such as methanol, butanol and ethanol and is optimally measured at $485 \mathrm{~nm}$ (Stevenson 1959). The assay can be used to determine cell viability (Tergendy et al. 1967) and for the analysis of microbial activity present in soils and other samples (Stevenson 1959). Like the FDA assay, the TTC assay estimates cell activity through enzyme activity. Due to its somewhat lower sensitivity, the TTC assay requires sample incubation periods of at least $24 \mathrm{~h}$ (Ishikawa et al. 1995). In addition, in the presence of $\mathrm{O}_{2}$ as a competing electron acceptor the dehydrogenase activity is potentially underestimated (Von Mersi and Schinner 1991). Therefore, samples analysed by the TTC assay in this study were incubated statically for 1 week. The TTC results are in good agreement with the findings of the FDA assay (Fig. 1). Addition of glucose confirmed the presence of glucose utilising microorganisms by leading to higher overall dehydrogenase activity due to increased microbial biomass (Fig. 1b). This is expected since gut microorganisms in ungulates ultimately break down cellulose to glucose. The high dehydrogenase and hydrolase activity of zebra faeces in the presence of a slightly elevated $\mathrm{pH}$ might indicate the presence of microorganisms therein able to function at higher than neutral $\mathrm{pH}$, possibly indicating the presence of enzymes with potential for use in industrial applications requiring alkaline conditions (Horikoshi 1999). Comparison of sample $\mathrm{pH}$ values (Table 1) and TPF formation rates (Fig. 1b) indicates that increased TPF formation took place at neutral to slightly alkaline $\mathrm{pH}$ (i.e. $\mathrm{pH}>7$ ), confirming previous studies showing that the activity of electron transport systems (ETS)-including dehydrogenase activity-is enhanced within a $\mathrm{pH}$ range of 7.4-8 (Trevors 1984).

\section{Microbial counts}

Viable counts in faecal samples were mostly in the range of $10^{8}$ cells per gram dry weight, with each faecal sample containing all targeted hydrolase producers although strictly anaerobic hydrolytically active bacteria were not quantified (Table 2). The counts for soil control samples were generally at least $1-2 \operatorname{logs}$ lower than the counts in the corresponding faecal samples. In addition, clear differences in the proportions of specific hydrolase producers were evident (Fig. 2). Gong (2007) reported total and viable microscopic counts for cattle dung of about $10^{11} \mathrm{cfu} / \mathrm{g}$ (dry weight) and a matching plate count for mesophilic aerobic and facultatively anaerobic bacteria of about $10^{10} \mathrm{cfu} / \mathrm{g}$, with proteolytic bacteria present at about $10^{8} \mathrm{cfu} / \mathrm{g}$ and both lipolytic, amylolytic and cellulolytic bacteria present at about $10^{9} \mathrm{cfu} / \mathrm{g}$. Viable plate counts established in this study for Nguni cow faeces were lower than those reported by Gong (2007), although similar relative proportions were observed for the hydrolase producers with the exception of cellulolytic microorganisms. The difference in viable counts per $g$ of faeces might be due to the shorter incubation time for agar plates used and the typically poorer diet of the Nguni cow (Tada et al. 2013).

With the exception of lipolytic esterase producing organisms, faecal samples from impala and giraffe showed similar proportions of amylase, cellulose and protease-producers (Fig. 2). Both impala and giraffe, ruminants as opposed to the non-ruminant zebra, had relative proportions of 91 and $95 \%$ for amylase producers, 89 and $93 \%$ of protease producers and fairly similar percentages of cellulase producers (52 and $74 \%$ ). Zebra in turn had the highest proportion of esterase producers (72\%) and the lowest proportion of protease and cellulase producers (17 and $21 \%$ ) amongst the three ungulates. In comparison, Nguni faeces was similar to zebra faeces with a fairly high proportion of amylase producers (46\%), a low proportion of protease producers (4.3\%) and an almost identical proportion of cellulose producers (22\%) present. Nguni faeces displayed lower hydrolytic and dehydrogenase activity compared to other ungulates, which could be due to lower proportions of hydrolase producers present and the different digestive system. These findings are consistent with previous reports in the literature suggesting that cellulolytic microorganisms when in competition with other specialists are present at low proportions (Witten and Richardson 2003). The different digestive systems present in ruminants (for example giraffe) and hindgut digesters such as zebra might result in different microbial communities.

A study of the giraffe rumen microbiome by Roggenbuck et al. (2014) showed via sequence analysis that in addition to many unknown bacteria, strictly anaerobic bacteria constitute a large proportion of the rumen community and that diet might influence the composition of this community.

The apparent differences in microbial colony counts and diversity of hydrolytically active bacteria within faeces from different herbivores (Table 2) might be due to their different feeding habits. Zebra and Nguni cattle are grazers (Odadi et al. 2011) whilst giraffe is a browser and impala is a mixed feeder (grazer and browser) (Codron et al. 2005). In Nguni cow and zebra faeces the proportion of esterase producers was higher than in faeces of giraffe and impala (Fig. 2) while the opposite applies to 
the proportion of cellulose producers which was lower in cow and zebra faeces than in faeces from giraffe and impala. Grazers feed more on grasses that are considered less nutritious than other forage and grazing is a lengthier process than browsing (Udén and Van Soest 1982). Zebra faeces, however, displayed a higher hydrolytic activity than Nguni cow faeces (Fig. 1a) which may be due to the difference in their digestive systems and the microbial community present. As large sized ruminants, cows have a longer digestion than non-ruminants and require more grazing time. Hydrolytic microorganisms from cattle form biofilms on forage substrates within the rumen to efficiently hydrolyse polymeric substrates (McSweeney et al. 1999) with an efficient digestion of biopolymers such as cellulose taking place in the foregut, mostly facilitated by anaerobic microorganisms. Movement of cud to the hindgut is usually required for secondary digestion. As a result, lower counts for aerobic microorganisms and hydrolase producers are expected in cow faeces (Mackie 2002). Although grass diets of cow and zebra are similar, zebra as hindgut fermenters possess an advantage by feeding on greater forage variety for shorter periods (Odadi et al. 2011). Zebra living in the local nature reserve probably had access to a more diverse diet than the Nguni cow kept at a local farm.

This study indicates that relative proportions of hydrolase producers in faeces-even though strictly anaerobic hydrolase producers were not quantified-are mostly similar for comparable feeding habits while hydrolytic activities and microbial loads can differ. This might be a result of different digestive systems and digestion times. The data for cattle and zebra indicate somewhat higher numbers of viable microorganisms in equine than in bovine faeces possibly due to shorter retention time (Odadi et al. 2011) resulting in less efficient polymer hydrolysis. As digestion occurs within the hindgut, forage is usually defecated without being properly hydrolysed resulting in more faecal shedding in zebra (Mackie 2002) than in cattle, as indicated by the results in this study.

Impala and giraffe appear to be similar regarding the relative proportions of protease, cellulose and amylase producers. As ruminants, they have a more complex digestive system than zebra and as browsers a more diverse diet. The impala in this study might have fed on a diet similar to the diet of giraffe, comprising of more browse forage than grasses, resulting in mostly similar relative hydrolase producer proportions. The smaller body size of impala means that digestion time is shorter compared to cows and faecal microbial numbers may therefore be higher (Gordon 2003).

The presence of proportionally more lipolytic esterase producers in zebra and Nguni cow than in impala and giraffe faeces might be due to the varying lipid content of plant species (Hadley and Rosen 1974) included in their diet. The presence of protease producers in faeces-although at a lower relative proportion in zebra and cow faeces-was expected, as proteases are present in the majority of heterotrophic microorganisms. Similarly, cellulose and amylase producing microorganisms were observed which is expected based on the presence of large amounts of cellulose and starch in leaves and grasses (Ben-Shahar and Coe 1992). Apart from the hydrolases targeted in this study, other hydrolytic enzymes which are of interest for industry (Kirk et al. 2002) such as xylanases and hemicellulases are typically detected in faecal samples of ungulates (Fon and Nsahlai 2012).

Microbial interactions in the intestinal systems of these herbivores are similar to anaerobic bioreactors utilizing cellulosic material as substrate, with similar hydrolytically active bacteria documented as members of the anaerobic food chain in artificial (bioreactors) and natural systems (digestive tract of herbivores) (Krakat et al. 2011; Morrison et al. 2009).

\section{Conclusions}

The detection of large numbers of proteolytic, cellulolytic, amylolytic and lipolytic bacteria in faecal matter from zebra, giraffe and impala indicates that this material is a useful source for the isolation of hydrolase producing microorganisms. Zebra, giraffe and impala faeces appeared more promising than cattle faeces and soil controls due to generally higher numbers of microbial hydrolysers and higher overall hydrolytic activity. This study used a culture-based approach to screen for the presence of specific hydrolase producers present in herbivore faeces. A metagenomics approach targeting genes encoding for hydrolytic enzymes in these samples could be a potential experimental technique to evaluate such faeces as source for additional hydrolases.

\section{Methods}

\section{Sample collection}

Fresh faecal samples from zebra, giraffe and impala were collected on four different occasions (January 2011January 2012) at the Bisley Valley Nature Reserve in Pietermaritzburg (S29 $39^{\prime} 44^{\prime \prime}$, E30 $\left.23^{\prime} 25^{\prime \prime}\right)$. Soil samples near faecal collection points and fresh faeces from pasture-fed Nguni cows (Ukulinga Research Farm, UKZN, Pietermaritzburg) were used for comparison. All soil and faecal samples were collected in sterile plastic bags, transported on ice and then stored at $4{ }^{\circ} \mathrm{C}$. Samples were analysed in the laboratory on the same day within $6 \mathrm{~h}$ after collection. 


\section{Moisture content}

About $1 \mathrm{~g}$ of sample material was dried in an oven at $105{ }^{\circ} \mathrm{C}$ for $48 \mathrm{~h}$. Samples were then cooled to room temperature, reweighed and the percentage moisture content was established.

\section{Soluble chemical oxygen demand}

The soluble organic fraction in fresh faeces and soil samples was quantified as soluble chemical oxygen demand (sCOD). 100 fold dilutions of $1 \mathrm{~g}$ of fresh sample material in distilled water were homogenised (shaking at $150 \mathrm{rpm}$ for $20 \mathrm{~min}$ ), centrifuged ( $5 \mathrm{~min}$ at $10,000 \times g$ ) and then used to determine the SCOD as reported previously (Gemmell and Schmidt 2012). Values were established as mg of sCOD per gram dry weight.

\section{Measurement of $\mathrm{pH}$}

The $\mathrm{pH}$ of samples was measured according to ISO 10390 (2005) by adding $50 \mathrm{ml}$ of $0.1 \mathrm{M}$ calcium chloride solution to $10 \mathrm{~g}$ of air-dried ( $48 \mathrm{~h}$ in the dark) homogenised sample material. Measurements were done using a calibrated $\mathrm{pH}$ electrode (Crison, MicropH 2001, USA) after $5.5 \mathrm{~h}$ incubation at $25^{\circ} \mathrm{C}$.

\section{Hydrolase and dehydrogenase activity}

Overall hydrolytic activity in samples was quantified using a modified fluorescein diacetate (FDA) assay essentially following the procedure reported by Green et al. (2006), while the dehydrogenase activity in samples was determined using the triphenyltetrazolium chloride (TTC) assay (Stevenson 1959). The FDA assay was carried out in duplicate Erlenmeyer flasks containing $50 \mathrm{ml} 60 \mathrm{mM}$ sodium phosphate buffer ( $\mathrm{pH} 7.6), 0.5 \mathrm{ml}$ FDA ( $4.8 \mathrm{mM}$ in acetone) and $1 \mathrm{~g}$ of fresh sample material followed by incubation for $1.5 \mathrm{~h}$ in the dark at $30{ }^{\circ} \mathrm{C}$, either statically in a thermo-controlled incubator or at $150 \mathrm{rpm}$ in a thermo-controlled shaker. Reactions were terminated by adding $2 \mathrm{ml}$ acetone, followed by centrifugation $(20,000 \times g, 5 \mathrm{~min})$, measuring the absorbance at $490 \mathrm{~nm}$ (Shimadzu 1240) and extrapolating fluorescein concentrations using calibration curves established using authentic fluorescein. Hydrolase activities were established as $\mu \mathrm{g}$ of fluorescein formed per gram dry weight per hour of incubation. Appropriate controls (flasks with sample material and no FDA and flasks with only phosphate buffer and FDA) were always included and accounted for. For the TTC assay $7.5 \mathrm{ml}$ deionised water, $3 \mathrm{ml} 3 \%$ aqueous TTC and $6 \mathrm{~g}$ of fresh sample were mixed and incubated for 1 week in the dark at ambient temperature. Additional incubations were done with $0.1 \mathrm{~g}$ glucose added as substrate to verify the presence of glucose utilizing microorganisms. Triphenylformazan (TPF) was extracted from samples using methanol and quantified with absorbance measured at $485 \mathrm{~nm}$ and by using standard curves established using authentic TPF. The dehydrogenase activities were reported as $\mu \mathrm{g}$ of TPF formed per gram dry weight.

\section{Bacterial enumeration}

Viable counts of heterotrophic bacteria were determined via spread plating onto plate count (PC) agar (Merck). Decimal dilutions of environmental samples (ranging from $10^{-1}$ to $10^{-8}$ ) were established by initially adding $10 \mathrm{~g}$ of sample material to $90 \mathrm{ml}$ peptone water (8.5 $\mathrm{g} \mathrm{NaCl}$ and $1 \mathrm{~g}$ peptone per litre, $\mathrm{pH}$ 7.0) followed by homogenisation at $150 \mathrm{rpm}$ for $15 \mathrm{~min}$ and subsequent decimal dilutions up to $10^{-8}$. Samples $(100 \mu \mathrm{l})$ from each decimal dilution were then spread-plated in triplicate onto PC agar; Tween 80 agar (5 g peptone, $3 \mathrm{~g}$ meat extract, $10 \mathrm{ml}$ Tween $80,100 \mathrm{mg} \mathrm{CaCl} \mathrm{Cl}_{2} \times 2 \mathrm{H}_{2} \mathrm{O}$ and $15 \mathrm{~g}$ agar per litre, $\mathrm{pH}$ 7.2); skim milk agar (10 g skim milk powder, $3 \mathrm{~g}$ meat extract, $5 \mathrm{~g} \mathrm{NaCl}, 2 \mathrm{~g} \mathrm{Na} \mathrm{HPO}_{4}$, $15 \mathrm{~g}$ agar and $0.05 \mathrm{~g}$ bromothymol blue per litre, $\mathrm{pH}$ 7.2); carboxymethylcellulose agar (CMC agar) (2 $\mathrm{g} \mathrm{NaNO}_{3}, 1 \mathrm{~g}$ $\mathrm{K}_{2} \mathrm{HPO}_{4}, 0.6 \mathrm{~g} \mathrm{MgSO}_{4}, 0.6 \mathrm{~g} \mathrm{KCl}, 2$ g carboxymethylcellulose sodium salt, $0.2 \mathrm{~g}$ peptone and $17 \mathrm{~g}$ agar per litre, $\mathrm{pH}$ 7.2) and starch agar (3 g beef extract, $10 \mathrm{~g}$ soluble starch and $12 \mathrm{~g}$ agar per litre, $\mathrm{pH}$ 7.2). Colony counts were established after incubation for $48 \mathrm{~h}$ at a temperature of $30{ }^{\circ} \mathrm{C}$ as suggested by Gong (2007). CMC and starch agar plates were flooded with Gram's iodine solution to detect cellulase and amylase positive colonies displaying a clear halo; protease positive colonies displayed blue colour due to casein hydrolysis on skim milk agar; esterase positive colonies on Tween 80 agar produced calcium oleate precipitates.

\section{Authors' contributions}

LLN carried out the analysis of droppings, LLN and SS jointly designed the study and analysed and interpreted the data. Both authors read and approved the final manuscript.

\section{Acknowledgements}

This project was supported in part by funding obtained from the National Research Foundation of South Africa (SS).

\section{Competing interests}

The authors declare that they have no competing interests.

Received: 19 October 2015 Accepted: 18 January 2016 Published online: 09 February 2016

\footnotetext{
References

Abubakar BSUI, Ismail N (2012) Anaerobic digestion of cow dung for biogas production. ARPN J Eng Appl Sci 7:169-172

Adam G, Duncan H (2001) Development of a rapid and sensitive method for the measurement of total microbial activity using fluorescein diacetate (FDA) in a range of soils. Soil Biol Biochem 33:943-951

Artan R, Cook DF, Dadour IR, Ali DN (1996) Effect of diet on the excretion profile of ivermectin in cattle faeces. Int J Parasitol 3:291-295
} 
Battin TJ (1997) Assessment of fluorescein diacetate hydrolysis as a measure of total esterase activity in natural stream sediment biofilms. Sci Total Environ 198:51-60

Ben-Shahar R, Coe MJ (1992) The relationships between soil factors, grass nutrients and the foraging behaviour of wildebeest and zebra. Oecologia 90:422-428

Bhaskar N, Benila T, Radha C, Lalitha RG (2008) Optimization of enzymatic hydrolysis of visceral waste proteins of Catla (Catla catla) for preparing protein hydrolysate using a commercial protease. Bioresour Technol 99:335-343

Blackburn TH, Hobson PN (1962) Further studies on the isolation of proteolytic bacteria from the sheep rumen. J Gen Microbiol 29:69-81

Bozic N, Ruiz J, Lopez-Santin J, Vujcic Z (2011) Optimization of the growth and a-amylase production of Bacillus subtilis IP 5832 in shake flask and laboratory fermenter batch cultures. J Serb Chem Soc 76:965-972

Cherry JR, Fidantsef AL (2003) Directed evolution of industrial enzymes: an update. Curr Opin Biotechnol 14:438-443

Chrzanowski TH, Crotty RD, Hubbard JG, Welch RP (1984) Applicability of the fluorescein diacetate method for detecting active bacteria in freshwater. Microb Ecol 10:179-185

Clarke JM, Gillings MR, Altavilla N, Beattie AJ (2001) Potential problems with fluorescein diacetate assays of cell viability when testing natural products for antimicrobial activity. J Microbiol Methods 46:261-267

Codron D, Codron J, Sponheimer M, Lee-Thorp JA, Robinson T, Grant CC, De Ruiter D (2005) Assessing diet in savanna herbivores using stable carbon isotope ratios of faeces. Koedoe 48:115-124

De Garine-Wichatitsky M, Fritz H, Gordon IJ, Illius AW (2004) Bush selection along foraging pathways by sympatric impala and greater kudu. Oecologia 141:66-75

Doi RH (2008) Cellulases of mesophilic microorganisms: cellulosome and noncellulosome producers. Ann NY Acad Sci 1125:267-279

Fon FN, Nsahlai IV (2012) The in vitro fermentation of maize stover as affected by faecal bacteria obtained from ungulates. S Afr J Anim Sci 42:478-482

Gemmell ME, Schmidt S (2012) Microbiological assessment of river water used for the irrigation of fresh produce in a sub-urban community in Sobantu, South Africa. Food Res Int 47:300-305

Gong C (2007) Microbial safety control of compost material with cow dung by heat treatment. J Environ Sci 19:1014-1019

Gordon IJ (2003) Browsing and grazing ruminants: are they different beasts? For Ecol Manag 181:13-21

Green VS, Stott DE, Diack M (2006) Assay for fluorescein diactetate hydrolytic activity: optimization for soil samples. Soil Biol Biochem 38:693-701

Gupta R, Beg QK, Lorenz P (2002) Bacterial alkaline proteases: molecular approaches and industrial applications. Appl Microbiol Biotechnol 59:15-32

Hadley EB, Rosen RB (1974) Carbohydrate and lipid contents of Celmisia plants in alpine snowbank and herbfield communities on Rock and Pillar Range, New Zealand. Am Midl Nat 91:371-382

Hartemink AE (2006) Assessing soil fertility decline in the tropics using soil chemical data. Adv Agron 89:179-225

Hartemink AE (2007) Soil fertility decline: definitions and assessment. In: Lal R (ed) Encyclopaedia of soil science, 2nd edn. Taylor \& Francis, Netherlands, pp 1618-1621. doi:10.1081/E-ESS-120041235

Horikoshi K (1999) Alkaliphiles: some applications of their products for biotechnology. Microbiol Mol Biol Rev 63:735-750

International Standard Organization (2005) ISO 10390. Soil quality-determination of $\mathrm{pH}$, 2nd edn. International Organization for Standardization, Geneva

Ishikawa M, Robertson AJ, Gusta LV (1995) Comparison of viability tests for assessing cross-adaptation to freezing, heat and salt stresses induced by abscisic acid in bromegrass (Bromus inermis Leyss) suspension cultured cells. Plant Sci 107:83-93

Juergensmeyer MA, Nelson ES, Juergensmeyer EA (2007) Shaking alone, without concurrent aeration, affects the growth characteristics of Escherichia coli. Lett Appl Microbiol 45:179-183

Juturu V, Wu JC (2014) Microbial cellulases: engineering, production and applications. Renew Sustain Energy Rev 33:188-203

Keesing F (1998) Impact of ungulates on the demography and diversity of small mammals in central Kenya. Oecologia 116:381-389

Kirk O, Borchert TV, Fuglsang CC (2002) Industrial enzyme applications. Curr Opin Biotechnol 13:345-351
Krakat N, Schmidt S, Scherer P (2011) Potential impact of process parameters upon the bacterial diversity in the mesophilic anaerobic digestion of beet silage. Bioresour Technol 102:5692-5701

Laho T, Váradyová Z, Mihaliková K, Kišidayová S (2012) Fermentation capacity of faecal microbial inocula of Przewalski horse, Kulan, and Chapman zebra and polysaccharide hydrolytic activities of faecal microbial constituents (ciliates and bacteria) of Kulan and Chapman zebra. J Equine Vet Sci 33:143-149

Lundgren B (1981) Fluorescein diacetate as a stain of metabolically active bacteria in soil. Oikos 36:17-22

Mackie RI (2002) Mutualistic fermentative digestion in the gastrointestinal tract: diversity and evolution. Integr Comp Biol 42:319-326

Marãnón E, Castrillón L, Fernández JJ, Fernández Y, Peláez Al, Sánchez J (2006) Anaerobic mesophilic treatment of cattle manure in an upflow anaerobic sludge blanket reactor with prior pasteurization. J Air Waste Manag Assoc 56(137-143):34

Mcsweeney CS, Dalrymple BP, Gobius KS, Kennedy PM, Krause DO, Mackie RI, Xue GP (1999) The application of rumen biotechnology to improve the nutritive value of fibrous feedstuffs: pre- and post-ingestion. Livest Prod Sci 59:265-283

Moran J (2005) Tropical dairy farming: feeding management for small holder dairy farmers in the humid tropics. CSIRO Publishing, Melbourne

Morrison M, Pope PB, Denman SE, Mcsweeney CS (2009) Plant biomass degradation by gut microbiomes: more of the same or something new? Curr Opin Biotechnol 20:358-363

Odadi WO, Jain M, Van Wieren SE, Prins HHT, Rubenstein DI (2011) Facilitation between bovids and equids on an African savanna. Evol Ecol Res 13:237-252

Pellew RA (1984) Food consumption and energy budgets of the giraffe. J Appl Ecol 21:141-159

Ray RR (2011) Microbial isoamylases: an overview. Am J Food Technol 6:1-18

Roggenbuck M, Sauer C, Poulsen M, Bertelsen MF, Sørensen SJ (2014) The giraffe (Giraffa camelopardalis) rumen microbiome. FEMS Microbiol Ecol 90:237-246

Sadhu S, Saha P, Mayilraj S, Maiti TK (2011) Lactose-enhanced cellulase production by Microbacterium sp. isolated from faecal matter of Zebra (Equus zebra). Curr Microbiol 62:1050-1055

Sanchez-Porro C, Martin S, Mellado E, Ventosa A (2003) Diversity of moderately halophilic bacteria producing extracellular hydrolytic enzymes. J Appl Microbiol 94:25-300

Schnurer J, Rosswall T (1982) Fluorescein diacetate as a measure of total microbial activity in soil and litter. Appl Environ Microbiol 43:1256-1261

Stevenson IL (1959) Dehydrogenase activity in soils. Can J Microbiol 5:229-235

Swisher R, Carroll GC (1980) Fluorescein diacetate hydrolysis as an estimator of microbial biomass on coniferous needle surfaces. Microb Ecol 6:217-226

Tada O, Muchenje V, Dzama K (2013) Preferential traits for breeding Nguni cattle in low-input in-situ conservation production systems. SpringerPlus 2:195

Tergendy RP, Nagy JG, Martin B (1967) Quantitative measurement of bacterial growth by reduction of tetrazolium salts. Appl Microbiol 15:954-955

Trevors J (1984) Effect of substrate concentration, inorganic nitrogen, $\mathrm{O}_{2}$ concentration, temperature and $\mathrm{pH}$ on dehydrogenase activity in soil. Plant Soil 77:285-293

Udén P, Van Soest PJ (1982) Comparative digestion of timothy (Phleum pratense) fibre by ruminants, equines and rabbits. Br J Nutr 47:267-272

Varel VH, Fryda SJ, Robinson IM (1984) Cellulolytic bacteria from pig large intestine. Appl Environ Microbiol 47:219-221

Von Mersi W, Schinner F (1991) An improved and accurate method for determining the dehydrogenase activity of soils with iodonitrotetrazolium chloride. Biol Fertil Soils 11:216-220

Wanandy S, Brouwer N, Liu Q, Mahon A, Cork S, Karuso P, Vemulpad S, Jamie $J$ (2005) Optimisation of the fluorescein diacetate antibacterial assay. J Microbiol Methods 60:21-30

Witten GQ, Richardson FD (2003) Competition of three aggregated microbial species for four substrates in the rumen. Ecol Model 164:121-135

Ziemer CJ, Kerr BJ, Weber TE, Arcidiacono S, Morrison M, Ragauskas A (2012) Effects of feeding fiber-fermenting bacteria to pigs on nutrient digestion, faecal output and plasma energy metabolites. J Anim Sci 90:4020-4027 